\title{
The Impact of Community Engagement on Health, Social, and Utilization Outcomes in Depressed, Impoverished Populations: Secondary Findings from a Randomized Trial
}

\author{
Christine A. Lam, MD, MBA, Cathy Sherbourne, PhD, Lingqi Tang, PhD, \\ Thomas R. Belin, PhD, Pluscedia Williams, BA, Angela Young-Brinn, MBA, \\ Jeanne Miranda, PhD, and Kenneth B. Wells, MD, MPH
}

Background: Disparities in depression care exist among the poor. Community Partners in Care (CPIC) compared a community coalition model with technical assistance to improve depression services in under-resourced communities. We examine effects on health, social, and utilization outcomes among the poor and, non-poor depressed, and poor subgroups.

Methods: This study analyzed clients living above $(n=268)$ and below $(n=750)$ the federal-poverty level and, among the poor, 3 nonoverlapping subgroups: justice-involved $(n=158)$, homeless and not justice-involved $(n=298)$, and other poor $(n=294)$. Matched programs $(n=93)$ from health and community sectors were randomly assigned to community engagement and planning (CEP) or resources for services (RS). Primary outcomes were poor mental health-related quality of life and 8-item Patient Health Questionnaire scores, whereas community-prioritized and utilization outcomes were secondary. Effects were scrutinized using false discovery rate-adjusted $P$ values to account for multiple comparisons.

Results: In the impoverished group, CEP and RS clients of participating study programs did not differ in primary outcomes, but CEP more than RS improved mental wellness among the depressed poor (unadjusted $P=.004$ ) while providing suggestive evidence for other secondary outcomes. Within the poor subgroups, evidence favoring CEP was only suggestive but was strongest among justice-involved clients.

Conclusions: A coalition approach to improving outcomes for low-income clients with depression, particularly those involved in the justice system, may offer additional benefits over standard technical assistance programs. (J Am Board Fam Med 2016;29:325-338.)

Keywords: Depression; Health Care Disparities; Homelessness; Populations, Underserved; Social Determinants of Health

Depression is associated with increased morbidity and physical health comorbidity. ${ }^{1,2}$ While prevalence of depressive symptoms is similar across cul-

This article was externally peer reviewed.

Submitted 15 September 2015; revised 19 January 2016; accepted 27 January 2016.

From the Veterans Administration Health Services Research and Development Center for the Study of Healthcare Innovation, Implementation and Policy, Veterans Administration Greater Los Angeles Healthcare System, Sepulveda, CA (CAL); the Departments of Medicine (CAL) and Psychiatry and Biobehavioral Sciences (TRB, KBW), David Geffen School of Medicine, University of California, Los Angeles, Los Angeles (CAL); RAND Corp., Santa Monica, CA (CS, KBW); the Center for Health Services and Society, University of California, Los Angeles, Los Angeles (LT, JM, KBW); the Departments of Biostatistics (TRB) and Health Policy and Management $(\mathrm{KBW})$, Jonathan and Karin Fielding School of tural groups, ${ }^{3}$ ethnic minorities and persons of lower socioeconomic status have worse access to evidence-based care and worse outcomes than

Public Health, University of California, Los Angeles, Los Angeles; Healthy African American Families II, Los Angeles, CA (PW); the Department of Research, Charles R. Drew University of Medicine and Science, Los Angeles, CA (PW); and the J.D. Pacada Foundation, Los Angeles, CA (AY-B)

Funding: These analyses of Community Partners in Care data were supported by the National Institute on Minority Health and Health Disparities (grant no. R01MH078853; P.I.s JM, KBW) and the Patient-Centered Outcomes Research Institute (award no. 1845; P.I. KBW). The parent study was funded by the National Institute of Mental Health (award no. R01MH078853, P30MH082760, and P30MH068639); the Robert Wood Johnson Foundation (award no. 64244), the California Community Foundation (award no. CMCH-12-97088), the National Library of Medicine (award no. G08LM011058), and the National Institutes 
white populations. ${ }^{4,5}$ Quality improvement (QI) programs for depression in primary care, such as the collaborative care model, ${ }^{6}$ are effective in minority and low-income communities. ${ }^{7-16}$ Miranda et $\mathrm{al}^{17}$ demonstrated that depression treatments are effective for socioeconomically vulnerable, minority women, whereas Partners in Care found greater benefits under collaborative care compared with usual care for African Americans and Latinos relative to non-Hispanic whites across 5 years of follow-up. ${ }^{16,18}$ Such interventions are not widely available in safety-net practices, despite calls for implementation in policy sectors. ${ }^{19}$ National studies demonstrate persistent racial and ethnic disparities in access to and quality of depression care. ${ }^{20}$

Participatory coleadership with patient and community stakeholders is recommended for engaging under-resourced communities in improving their health. ${ }^{21,22}$ Community Partners in Care (CPIC) found that a Community Engagement and Planning (CEP) intervention, cultivating multiagency networks as a community coalition to implement QI interventions for depression across health and community sectors, was more effective at improving mental health quality of life (MHQOL) and reducing hospitalizations over 6 to 12 months than was Resources for Services (RS), which made expert assistance available to individual agencies. ${ }^{14,23}$ This article examines the extent to which the effects of CEP over RS for the whole sample also applied to persons living in poverty and to nonpoor participants, and it explores intervention effects for specific subgroups of the poor of clinical and policy interest.

\section{CPIC Intervention}

Community-partnered participatory research was used to design and implement the CPIC study and guide development of the CEP community coalition intervention to enhance depression services. Clients were recruited from programs delivering

of Health/National Center For Advancing Translational Science UCLA CTSI (award no. UL1TR000124). CAL is supported by the VA Quality Scholars program.

Conflict of interest: none declared.

Disclaimer: The contents of this article are solely the responsibility of the authors and do not necessarily represent the views of the funders.

Corresponding author: Christine A. Lam, MD, MBA, VA Greater Los Angeles Healthcare System, 11301 Wilshire Blvd (111G), Room 3233, Los Angeles, CA 90073 (E-mail: christinealam@mednet.ucla.edu). health (mental health, primary care, public health, substance abuse) and/or social and community services (homeless-services, prisoner reentry, family preservation and faith-based programs, community centers, hair salons, and exercise clubs). ${ }^{24}$ Two implementation interventions were developed by academic and community partners. Program administrators, providers, and community and academic study leaders in CEP used an intervention work group to conduct biweekly meetings for 5 months to develop and implement a written plan for engaging groups of providers in training based on existing QI toolkits (eg, clinical assessments, medication management, case management, cognitivebehavioral therapy manuals, and patient education materials), with efforts to build a coalition for depression care. ${ }^{14}$ By contrast, RS provided technical assistance through written and online resources and a series of 12 "train-the-trainer" webinars, plus primary care site visits to support toolkit implementation. Relative to RS, CEP increased the participation of eligible staff in depression training. ${ }^{25}$ Over 6 months, relative to RS, CEP reduced the proportion of individuals who had poor MHQOL. For secondary outcomes, CEP (relative to RS) increased physical exercise, reduced risks for homelessness, and reduced behavioral health-related hospitalizations, ${ }^{14}$ while shifting outpatient visits for depression away from specialty mental health medication management toward depression services provided at faith-based centers and parkbased programs. ${ }^{23}$ Over 12 months, there were modest continuing benefits of CEP over RS in terms of a reduced proportion of individuals with poor MHQOL and fewer hospital stays for behavioral health, but some findings were sensitive to modeling assumptions in the data analysis. ${ }^{23}$ There were no significant comparative intervention effects on depressive symptoms or use of health care depression treatments over 6 to 12 months. CPIC is noted in a Cochrane review as the only study of the added value of a community coalition intervention to improve the health of minority communities over a noncoalition comparator. ${ }^{26}$

This article examines the extent to which the effects of CEP relative to RS on primary and secondary outcomes are confirmed among poor or nonpoor clients; it also explores effects of CEP over RS within 3 mutually exclusive subgroups of poor: (1) justice-involved, (2) clients at risk for homelessness but not justice-involved, and (3) other poor (ie, 
neither homeless nor justice-involved). Community leaders requested the inclusion of these subgroups during the study design process. For these analyses, health policy partners recommended examining mutually exclusive subgroups, focusing first on those who are justice-involved as understudied and relevant to policy, homeless who are not justice-involved as a distinct group for similar reasons, and other poor to provide findings across all impoverished participants. Subgroup analyses were considered exploratory and were done to inform future research and potentially clinical practice. Secondary outcomes explore related social risk factors, including stressful life events or difficulties, the reduction of which may improve mental health outcomes. ${ }^{27}$ Given the dearth of literature on socially disenfranchised groups, these secondary analyses, albeit exploratory, can provide guidance to the field.

\section{Methods}

CPIC, a group-level randomized comparative effectiveness trial, assessed the effectiveness of CEP compared with $\mathrm{RS}^{14}$ using a community-partnered participatory research approach ${ }^{28}$ that includes community and academic partner coleaders with equal authority in all aspects of research. The institutional review boards of RAND Corp. and participating agencies approved procedures. CPIC was funded (2007) before the inclusion of health services interventions in required clinical trial registration and was not considered a clinical trial by the National Institutes of Health since no experimental treatments were included. The design of the study is described elsewhere. ${ }^{14,23,24,29}$

\section{Sampling}

Agencies that serviced at least 15 clients/week, had $\geq 1$ staff member, and were not focused exclusively on psychotic disorders or home services were sampled from 2 Los Angeles (LA) communities (South LA, Hollywood Metro) with high minority populations and poverty rates. Comprehensive lists of services agencies and community partner recommendations within each community were used to identify mental health, primary care, substance abuse, social services, homeless, and other community agencies. Sixty eligible agencies were offered the opportunity to participate; 133 of 194 programs within those agencies were potentially eligible.
Within each community, programs or clusters were paired based on geographic location, service sector, size, population served, services provided, and funding. One of each pair was randomized to CEP and the other to RS. Following site visits to finalize enrollment, 93 programs from 50 consenting agencies were enrolled.

Within programs, clients were screened in waiting rooms or at events from March to November 2010. Staff who were blinded to agency intervention status approached 4645 adults (age $\geq 18$ years) on 2 or 3 days/program; 4440 (95.6\%) agreed to be screened for depression. Eligibility for the study included the ability to provide contact information and being depressed (eg, score $\geq 10$ on the 8 -item Patient Health Questionnaire). ${ }^{30}$ Of the 4440 adults screened, 1322 (29.8\%) were eligible and 1246 (94.3\%) were enrolled. Of the enrolled clients, 981 completed a baseline telephone survey; 759 and 733 completed the 6- and 12-month follow-up surveys, respectively. The CONSORT flowchart detailing inclusion and exclusion is presented elsewhere. ${ }^{14}$ The most common reason for exclusion at different waves of follow-up was inability to contact.

Our analytic sample includes 1018 participants (81.9\% of those who consented minus those who died) with baseline or follow-up data, of whom 268 lived above and 750 below the federal poverty level (FPL). Of the 750 poor participants, we created mutually exclusive subgroups in order of decreasing social disenfranchisement: (1) clients arrested or on probation in the 6-months before baseline $(\mathrm{n}=$ 158) ("justice-involved"); (2) clients who were homeless or had $\geq 2$ risk factors for homelessness, but who were not arrested or on probation in the 6-months before baseline ( $\mathrm{n}=298$ ); and (3) the remaining clients living below the FPL $(\mathrm{n}=294)$ (“other poor").

\section{Baseline Measures}

Baseline measures include age, sex, education, race/ ethnicity, current marital and work statuses, health insurance coverage, number of chronic medical conditions, and intervention assignment. Responses from the Mini-International Neuropsychiatric Interview ${ }^{31}$ were used to create an indicator for 12-month major depressive disorder. Alcohol abuse or use of illicit drugs were assessed by the 3-item AUDIT $^{32}$ and the 10-item Drug Abuse Screening Test $^{33}$ at follow-up. 


\section{Outcome Measures}

\section{Health Outcomes}

For CPIC, the 2 preplanned primary mental and physical health outcomes were (1) poor MHQOL, defined as 1 standard deviation below the population mean on the 12-item Short Form Health Survey Mental Health Composite, ${ }^{34}$ and (2) reduction of depressive symptoms on the 9-item Patient Health Questionnaire (PHQ-9). ${ }^{35}$ Following stakeholder input, community-prioritized outcomes were developed for mental wellness and good physical health. ${ }^{10}$

\section{Social Outcomes}

Community-prioritized social outcomes included current homelessness or living in a shelter, or having multiple risk factors for future homelessness (eg, no place to stay for $\geq 2$ nights in the past 6 months or eviction from a primary residence, financial crisis or food insecurity in the past 6 months). Expanded social factors included report of worry about cost keeping one from getting help for emotional problems and total number of life difficulties experienced of a total of 15 (eg, no place to stay, eviction, witness of violence, lost custody of a child, death of a loved one, worry that food would not last, arrest or on probation, fired or laid off, reduced work hours, loss of health insurance, financial problems, gave up trying to find work, arguments with others at work, arguments with others at home, and arguments with others not living with you).

\section{Service Utilization}

Use of health services over a 6-month period was evaluated before the 6- and 12-month follow-ups based on client self-report. Outcomes include utilization of the formal health care sector: nights spent in a behavioral health hospital; any mental health specialty (MHS) outpatient visits during which advice was given about medication for emotional or mental health problems such as depression; number of visits where counseling was received; any use of outpatient substance abuse services or stay in a residential treatment program for substance abuse problems; and any use of outpatient primary care or public health clinics (primary care provider). The number of visits in the informal sector (social services, religious institutions/programs, parks, hotlines, other, but not including mental health self-help) where clients re- port receiving help for depression or emotional problems was also included. Finally, the total number of outpatient contacts for depression in all sectors (formal and informal) was included.

\section{Statistical Methods}

Our analytic sample included 1018 individuals who completed $\geq 1$ survey at baseline, 6 months, or 12 months. We used item-level imputation for missing data and wave-level imputation for missing surveys to adjust findings to the observed analytic sample. We used weights to account for nonenrollment among eligible clients and attrition. ${ }^{14}$ All analyses, which were conducted using SUDAAN version 11.0.1 (RTI International, Research Triangle Park, NC: http://www.rti.org/sudaan/), account for clustering (clients within programs), ${ }^{36}$ weighting, and multiple imputations. ${ }^{37}$

We estimated 2 models using linear regression for continuous variables, logistic regression for binary variables, or Poisson regression for count outcome variables. Model 1 used the total sample $(\mathrm{N}=$ 1018) and estimated a poverty-by-intervention (CEP relative to RS) interaction model adjusted for age, education, race/ethnicity, 12-month depressive disorder, community, and the baseline status of each outcome. Model 2 was fit to the subset of those in poverty $(\mathrm{n}=750)$ and included indicators for justice-involved, homeless but not justice-involved, and other poor, each of which interacted with intervention status using the same set of predictors. Comparisons focused on the effects of interventions within subgroups (above or below the FPL and the 3 nonoverlapping subgroups among those below the FPL).

Viewing our analyses as encompassing aspects of what Benjamini and Yekutieli ${ }^{38}$ described as a problem in subgroup analysis regarding the comparison of 2 conditions and a problem involving multiple end points, we built on the false discovery rate (FDR) framework of Benjamini and Hochberg $^{39}$ as extended by Yekutieli and Benjamini ${ }^{40}$ by using FDR-adjusted $P$ values in interpreting results across a large number of regression analyses. ${ }^{38-40}$ FDR assesses whether the number of results with a significant unadjusted $P$ value (ie, without adjustment for multiple comparisons) is disproportionate to what would be expected as a result of chance variation; the FDR-adjusted $P$ value $\left(P_{\mathrm{FDR}}\right)$ can be interpreted as the threshold FDR value below which the particular null hypothesis in question 
Table 1. Baseline Characteristics of Depressed Clients by Family Income Status

\begin{tabular}{|c|c|c|c|c|}
\hline & $\begin{array}{c}\text { Overall } \\
(\mathrm{N}=1018)\end{array}$ & $\begin{array}{l}\text { Clients with Income } \\
\text { Not Below the FPL } \\
\quad(\mathrm{n}=268)\end{array}$ & $\begin{array}{l}\text { Clients with Income } \\
\text { Below the FPL } \\
(\mathrm{n}=750)\end{array}$ & $P$ Value \\
\hline Age (years) & $45.8 \pm 12.9$ & $46.6 \pm 13.7$ & $45.4 \pm 12.5$ & .36 \\
\hline Female sex & $595(57.0)$ & $150(54.7)$ & $445(57.9)$ & .48 \\
\hline Race/ethnicity & & & & .93 \\
\hline Hispanic & $409(41.0)$ & $107(40.8)$ & $302(41.1)$ & \\
\hline African American & $488(46.0)$ & $127(45.2)$ & $361(46.2)$ & \\
\hline Non-Hispanic white & $86(9.2)$ & $25(10.3)$ & $61(8.9)$ & \\
\hline Other & $35(3.8)$ & $8(3.6)$ & $27(3.9)$ & \\
\hline Married or living with a partner & $231(22.6)$ & $82(30.3)$ & $149(19.8)$ & $<.01$ \\
\hline Less than high school education & $446(43.6)$ & $94(35.2)$ & $352(46.6)$ & $<.01$ \\
\hline Working for pay & $205(20.0)$ & $91(33.5)$ & $114(15.1)$ & $<.01$ \\
\hline 12-Month depressive disorder & $629(61.9)$ & $159(59.1)$ & $470(62.9)$ & .33 \\
\hline PHQ-8 score & $15.0 \pm 4.1$ & $14.7 \pm 4.2$ & $15.1 \pm 4.1$ & .31 \\
\hline Poor mental health-related quality of life & $546(53.2)$ & $146(55.2)$ & $400(52.5)$ & .49 \\
\hline Mental wellness & $407(39.7)$ & $107(39.3)$ & $300(39.8)$ & .87 \\
\hline Good physical health & $759(74.3)$ & $210(77.7)$ & $548(73.0)$ & .12 \\
\hline$\geq 3$ Chronic health conditions & $548(54.7)$ & $151(57.9)$ & $397(53.6)$ & .31 \\
\hline No health insurance & $545(54.1)$ & $121(45.2)$ & $424(57.3)$ & $<.01$ \\
\hline Life difficulties total score of 1 & $4.1 \pm 2.8$ & $4.2 \pm 2.8$ & $4.0 \pm 2.7$ & .56 \\
\hline Hazardous drinker or alcohol use disorder & $248(24.5)$ & $66(24.2)$ & $182(24.6)$ & .91 \\
\hline Misused any drugs in past 6 months & $357(35.3)$ & $86(32.6)$ & $271(36.2)$ & .41 \\
\hline Involved in the justice system & $201(19.6)$ & $43(16.2)$ & $158(20.9)$ & .10 \\
\hline Homeless or $\geq 2$ risk for homelessness & $538(54.1)$ & $136(50.7)$ & $403(55.3)$ & .25 \\
\hline
\end{tabular}

Data are mean \pm SD or $\mathrm{n}(\%)$ unless otherwise indicated.

FPL, federal poverty level; PHQ-8, 8-item Patient Health Questionnaire; SD, standard deviation.

would be rejected. Results with $P_{\mathrm{FDR}}<.05$, which adjusts for multiple comparisons, are considered to be convincing evidence of a difference; consistent with rationales for adapting the interpretation of significance findings to contextual factors such as the nature of the intervention and the size of the sample, ${ }^{41}$ higher alternative $P_{\mathrm{FDR}}$ thresholds are considered as signaling suggestive evidence within a sensitivity analysis framework.

To broaden our understanding of patterns, we report Cohen's effect sizes (ESs). ${ }^{42,43}$ We reflect ESs through standardized predictions by intervention and subgroups generated from fitted regression models. ${ }^{44} \mathrm{We}$ also provide between-group differences, odds ratios, and incidence rate ratios with 95\% confidence intervals (CIs). For continuously scaled variables, ESs are estimated as the difference between 2 adjusted intervention group means divided by a pooled standard deviation from a random effects model accounting for the cluster-randomized design. ${ }^{45}$ For dichotomous outcomes, we provide Cohen's effect size index $b$, defined as the difference between 2 arcsine-transformed propor- tions, ${ }^{43}$ where $b$ values of $0.20,0.50$, and 0.80 are used to reflect small, medium, and large ESs, respectively.

\section{Results}

Baseline and demographic characteristics for the CEP and RS groups are similar for those above and below the FPL. Those in poverty relative to the nonpoor had a higher percentage of unmarried clients, had less education above high school, worked for less pay, and had less health insurance coverage (Table 1). Within each poor, socially disenfranchised subgroup, baseline demographic and clinical characteristics were similar for the CEP and RS arms. The justice-involved were more likely than the other subgroups to be male, not be working for pay, not to have health insurance, to have more total life events, and to have misused any drugs in the past 6 months. Other differences between groups are shown in Table 2. 
Table 2. Baseline Characteristics of Depressed Clients Whose Family Income Is Below the Federal Poverty Level $(n=750)$, by Vulnerable Subgroups

\begin{tabular}{|c|c|c|c|c|c|c|c|c|c|}
\hline & \multirow{2}{*}{$\begin{array}{l}\text { Subgroup 1: } \\
\text { Involved in } \\
\text { Justice System } \\
(1)(\mathrm{n}=158)\end{array}$} & \multirow{2}{*}{$\begin{array}{l}\text { Subgroup 2: } \\
\text { Homeless } \\
\text { Involved in } \\
\text { Justice System } \\
(\mathrm{n}=298)\end{array}$} & \multirow[b]{2}{*}{$\begin{array}{l}\text { Subgroup 3: Other } \\
\text { Poor }(\mathrm{n}=294)\end{array}$} & \multicolumn{3}{|c|}{$\begin{array}{l}P \text { Value (Pairwise } \\
\text { Comparison) }\end{array}$} & \multicolumn{3}{|c|}{ Group Test } \\
\hline & & & & 1 vs 2 & 1 vs 3 & 2 vs 3 & $x^{2}$ & df & $\begin{array}{c}P \\
\text { Value }\end{array}$ \\
\hline Age (years) & $43.0 \pm 10.6$ & $45.5 \pm 11.7$ & $46.7 \pm 14.1$ & .074 & .014 & .355 & 6.4 & 2 & .041 \\
\hline Female sex & $65(39.6)$ & $174(56.8)$ & $206(69.1)$ & $<.001$ & $<.001$ & .009 & 23.0 & 2 & $<.001$ \\
\hline Race/ethnicity & & & & .301 & $<.001$ & .048 & 17.6 & 6 & .007 \\
\hline Hispanic & $44(28.3)$ & $111(38.0)$ & $147(51.4)$ & & & & & & \\
\hline African American & $88(53.4)$ & $148(47.9)$ & $125(40.5)$ & & & & & & \\
\hline Non-Hispanic white & $17(12.0)$ & $29(10.4)$ & $15(5.4)$ & & & & & & \\
\hline Other & $9(6.3)$ & $10(3.7)$ & $8(2.7)$ & & & & & & \\
\hline $\begin{array}{l}\text { Married or living with a } \\
\text { partner }\end{array}$ & $25(16.0)$ & $51(16.7)$ & $74(25.4)$ & .845 & .039 & .010 & 8.3 & 2 & .016 \\
\hline $\begin{array}{l}\text { Less than high school } \\
\text { education }\end{array}$ & $65(40.8)$ & $129(42.2)$ & $157(54.5)$ & .795 & .007 & .003 & 13.0 & 2 & .002 \\
\hline Working for pay & $12(7.4)$ & $60(19.6)$ & $42(14.6)$ & .001 & .035 & .164 & 10.9 & 2 & .004 \\
\hline $\begin{array}{l}\text { 12-Month depressive } \\
\text { disorder }\end{array}$ & $106(67.5)$ & $201(68.0)$ & $163(54.9)$ & .911 & .008 & .004 & 9.9 & 2 & .007 \\
\hline PHQ-8 score & $15.2 \pm 4.3$ & $15.4 \pm 4.0$ & $14.6 \pm 3.9$ & .715 & .195 & .056 & 3.9 & 2 & .144 \\
\hline $\begin{array}{l}\text { Poor mental health-related } \\
\text { quality of life }\end{array}$ & $77(48.8)$ & $167(54.6)$ & $156(52.3)$ & .311 & .507 & .610 & 1.0 & 2 & .599 \\
\hline Mental wellness & $68(43.5)$ & $108(35.7)$ & $124(42.3)$ & .164 & .816 & .181 & 2.3 & 2 & .311 \\
\hline Good physical health & $118(74.5)$ & $218(73.3)$ & $212(71.9)$ & .854 & .682 & .742 & 0.2 & 2 & .898 \\
\hline $\begin{array}{l}\geq 3 \text { Chronic health } \\
\text { conditions }\end{array}$ & $82(53.1)$ & $166(56.0)$ & $149(51.3)$ & .609 & .769 & .341 & 0.9 & 2 & .630 \\
\hline No health insurance & $116(73.5)$ & $186(63.1)$ & $123(42.1)$ & .091 & $<.001$ & $<.001$ & 24.7 & 2 & $<.001$ \\
\hline $\begin{array}{l}\text { Life difficulties total score } \\
\text { of } 15\end{array}$ & $5.9 \pm 3.1$ & $5.0 \pm 2.2$ & $2.0 \pm 1.6$ & .006 & $<.001$ & $<.001$ & 582.3 & 2 & $<.001$ \\
\hline $\begin{array}{l}\text { Hazardous drinker or } \\
\text { alcohol use disorder }\end{array}$ & $49(31.9)$ & $82(27.7)$ & $51(17.2)$ & .392 & .003 & .004 & 11.1 & 2 & .004 \\
\hline $\begin{array}{l}\text { Misused any drugs in past } \\
6 \text { months }\end{array}$ & $97(61.5)$ & $111(37.3)$ & $63(21.2)$ & $<.001$ & $<.001$ & $<.001$ & 42.1 & 2 & $<.001$ \\
\hline
\end{tabular}

Data are mean \pm SD or $\mathrm{n}(\%)$ unless otherwise indicated.

PHQ-8, 8-item Patient Health Questionnaire.

\section{Model 1}

There are no significant intervention differences in primary outcomes (percentage of clients with poor MHQOL or PHQ-8 scores) among the nonpoor or poor (Table 3). Regarding community-prioritized outcomes among the poor, CEP over RS improved mental wellness at 6 months $(P=.004$; $P_{\mathrm{FDR}}=.027$; ES $\left.=0.27\right)$, with suggestive evidence of better physical health at 12 months $(P=$ $\left..019 ; P_{\mathrm{FDR}}=0.115 ; \mathrm{ES}=0.20\right)($ Table 3$)$. Regarding other secondary outcomes, there was suggestive evidence for reduced worry about cost of mental health services at 12 months among those in CEP relative to those in RS $(P=.033$; $\left.P_{\mathrm{FDR}}=.115 ; \mathrm{ES}=0.19\right)$. The percentage of clients hospitalized for behavioral health or with any mental health outpatient visits did not differ significantly by intervention status for clients in poverty, nor did the percentage attending any outpatient or residential substance abuse services (Table 4). There was suggestive evidence for a reduced number of MHS medication visits at 6 months among the poor in the CEP compared with RS $\left(P=.006 ; P_{\mathrm{FDR}}=.059 ; \mathrm{ES}=0.30\right)$. At 12 months, primary care provider visits by the poor increased in the CEP group relative to the RS group $\left(P=.004 ; P_{\mathrm{FDR}}=.049 ;\right.$ ES 0.23). There is suggestive evidence that CEP increased mean depression-specific visits in communitybased sectors at 6 and 12 months compared with RS (6 months: $P=.032 ; P_{\mathrm{FDR}}=.159 ; \mathrm{ES}=0.15$; 12 months: $P=.033 ; P_{\mathrm{FDR}}=.163 ; \mathrm{ES}=0.14$ ). No significant unadjusted $P$ value differences by intervention were found within the nonpoor 
Table 3. Health and Social Outcomes by Poverty Status and Intervention Assignment (Model 1)

\begin{tabular}{|c|c|c|c|c|c|c|c|c|}
\hline & \multicolumn{4}{|c|}{$\begin{array}{l}\text { Income Not Below the Federal Poverty Line } \\
\qquad(\mathrm{n}=268)\end{array}$} & \multicolumn{4}{|c|}{$\begin{array}{l}\text { Income Below the Federal Poverty Line } \\
\qquad(\mathrm{n}=750)\end{array}$} \\
\hline & RS & CEP & $\begin{array}{l}\text { CEP vs. RS, Test } \\
\quad(95 \% \mathrm{CI})\end{array}$ & ES & RS & CEP & $\begin{array}{l}\text { CEP vs. RS, OR } \\
(95 \% \mathrm{CI})\end{array}$ & ES \\
\hline Poor MHQOL (\%) & & & OR & & & & OR & \\
\hline 6-Month follow-up & $51.4(4.4)$ & $37.0(4.7)$ & $0.5(0.3-1.1)$ & 0.29 & $51.6(3.0)$ & $46.5(2.5)$ & $0.8(0.6-1.1)$ & 0.10 \\
\hline 12-Month follow-up & $45.3(4.9)$ & $42.4(5.8)$ & $0.9(0.5-1.6)$ & 0.06 & $52.2(3.0)$ & $45.7(3.2)$ & $0.8(0.6-1.1)$ & 0.13 \\
\hline PHQ-8 standard score (mean) & & & Difference & & & & Difference & \\
\hline 6-Month follow-up & $12.1(0.8)$ & $11.8(0.7)$ & $-0.2(-2.6-2.2)$ & 0.04 & $13.1(0.5)$ & $12.7(0.5)$ & $-0.4(-2.3-1.4)$ & 0.06 \\
\hline 12-Month follow-up & $10.9(0.9)$ & $10.9(0.8)$ & $0.0(-2.2-2.3)$ & 0.00 & $12.4(0.4)$ & $12.1(0.4)$ & $-0.3(-1.5-0.9)$ & 0.04 \\
\hline Mental wellness (\%) & & & OR & & & & OR & \\
\hline 6-Month follow-up & $40.1(4.9)$ & $49.0(6.5)$ & $1.5(0.6-3.4)$ & 0.18 & $31.6(3.0)$ & $44.6(2.6)$ & $1.8(1.2-2.7)^{*}$ & 0.27 \\
\hline 12-Month follow-up & $54.7(5.7)$ & $51.0(4.3)$ & $0.9(0.5-1.6)$ & 0.07 & $44.8(3.6)$ & $48.2(3.4)$ & $1.2(0.7-1.8)$ & 0.07 \\
\hline \multicolumn{9}{|l|}{ Good physical health (\%) } \\
\hline 6-Month follow-up & $78.1(4.3)$ & $80.2(3.9)$ & $1.2(0.5-2.5)$ & 0.05 & $73.5(2.8)$ & $76.4(2.2)$ & $1.2(0.8-1.7)$ & 0.07 \\
\hline 12-Month follow-up & $78.0(4.2)$ & $77.4(3.8)$ & $1.0(0.5-1.9)$ & 0.01 & $69.6(3.5)$ & $78.4(2.8)$ & $1.6(1.1-2.4)^{\dagger}$ & 0.20 \\
\hline \multicolumn{9}{|l|}{ Homeless/risk (\%) } \\
\hline 6-Month follow-up & $38.1(6.6)$ & $27.9(4.8)$ & $0.6(0.3-1.2)$ & 0.22 & $40.3(3.4)$ & $30.3(3.1)$ & $0.6(0.4-1.0)$ & 0.21 \\
\hline 12-Month follow-up & $25.7(4.1)$ & $31.0(5.3)$ & $1.3(0.7-2.5)$ & 0.12 & $33.8(3.6)$ & $35.7(3.5)$ & $1.1(0.8-1.6)$ & 0.04 \\
\hline \multicolumn{9}{|l|}{ Worried about cost (\%) } \\
\hline 6-Month follow-up & $29.5(4.5)$ & $32.2(5.8)$ & $1.1(0.5-2.7)$ & 0.06 & $33.0(2.7)$ & $29.6(2.6)$ & $0.9(0.6-1.2)$ & 0.07 \\
\hline 12-Month follow-up & $28.7(4.8)$ & $30.1(4.6)$ & $1.1(0.6-2.0)$ & 0.03 & $32.6(2.6)$ & $24.0(3.2)$ & $0.6(0.4-1.0)^{\dagger}$ & 0.19 \\
\hline $\begin{array}{l}\text { Life difficulties total score out } \\
\text { of } 15 \text { (mean) }\end{array}$ & & & Difference & & & & Difference & \\
\hline 6-Month follow-up & $3.0(0.3)$ & $2.7(0.3)$ & $-0.3(-1.0$ to 0.5$)$ & 0.12 & $3.0(0.2)$ & $2.7(0.1)$ & $-0.3(-0.7$ to 0.2$)$ & 0.12 \\
\hline 12-Month follow-up & $2.6(0.2)$ & $2.4(0.2)$ & $-0.2(-0.9$ to 0.4$)$ & 0.09 & $2.8(0.2)$ & $2.6(0.2)$ & $-0.2(-0.5$ to 0.2$)$ & 0.09 \\
\hline
\end{tabular}

Data are estimate (standard error) unless otherwise indicated.

Intervention-by-poverty status interaction models used multiple imputed data weighted for the sample eligible for enrollment and accounted for the design effect of the cluster randomization. A linear regression model was used for a continuous variable (presented as between-group difference) or a logistic regression model for a binary variable (presented as odds ratio [OR]), adjusted for the baseline status of the dependent variable, age, education, race/ethnicity, 12-month depressive disorder, and community; it accounted for the design effect of the cluster randomization. No significant interactions of intervention and poverty status were found for any of the outcome variables.

${ }^{*} P<.01$.

${ }^{\dagger} P<.05$.

CEP, Community Engagement and Planning; CI, confidence interval; ES, standardized effect size; MHQOL, mental health quality of life; RS, Resources for Services.

sample, and none of the interactions between poverty and intervention status emerged as significant in model 1 .

\section{Model 2}

Among subgroups of poor clients, no significant intervention differences were seen in poor MHQOL or in PHQ-9 scores (Table 5). Regarding community-prioritized health outcomes, no significant intervention effects were found among justice-involved clients. CEP relative to RS showed suggestive evidence of improved physical health at 12 months for the homeless who were not justiceinvolved $\left(P=.042 ; P_{\mathrm{FDR}}=.196 ; \mathrm{ES}=0.27\right)$ and improved mental wellness at 6 months for other poor $\left(P=.009 ; P_{\mathrm{FDR}}=.062 ; \mathrm{ES}=0.33\right)$. For the justice-involved group, CEP relative to RS showed suggestive evidence of reducing the percentage who were currently homeless or who had multiple homelessness risk factors at 6 months $(P=.036$; $\left.P_{\mathrm{FDR}}=.126 ; \mathrm{ES}=0.46\right)$ and evidence of reducing total life difficulties $\left(P=.017 ; P_{\mathrm{FDR}}=.120, \mathrm{ES}=\right.$ $0.44)$. An exploratory analysis showed evidence of an increase in having no place to stay for $\geq 2$ nights in a row in the past 6 months for 26 of 88 clients in the RS group (95\% CI, 15.0-36.4) versus 13 of 69 clients in CEP (95\% CI, 5.6-20.6). Similarly, on the single item asking about arrests or probation in 
Table 4. Service Utilization By Poverty Status and Intervention Assignment (Model 1)

\begin{tabular}{|c|c|c|c|c|c|c|c|c|}
\hline & \multicolumn{4}{|c|}{$\begin{array}{l}\text { Not Below the Federal Poverty Line } \\
\qquad(\mathrm{n}=268)\end{array}$} & \multicolumn{4}{|c|}{ Below the Federal Poverty Line $(\mathrm{n}=750)$} \\
\hline & RS & CEP & $\begin{array}{l}\text { CEP vs. RS, } \\
\text { Test }(95 \% \text { CI })\end{array}$ & ES & RS & CEP & $\begin{array}{l}\text { CEP vs. RS, } \\
\text { Test }(95 \% \mathrm{CI})\end{array}$ & ES \\
\hline $\begin{array}{l}\text { Spent nights in a behavioral health } \\
\text { hospital (\%) }\end{array}$ & & & OR & & & & OR & \\
\hline 6-Month follow-up & $10.9(4.0)$ & $5.4(2.6)$ & $0.5(0.2-1.3)$ & 0.20 & $10.4(2.2)$ & $5.9(1.6)$ & $0.5(0.3-1.1)$ & 0.17 \\
\hline 12-Month follow-up & $5.0(1.9)$ & $3.9(1.5)$ & $0.8(0.2-2.4)$ & 0.05 & $5.1(1.2)$ & $4.5(1.0)$ & $0.9(0.4-1.7)$ & 0.03 \\
\hline \multicolumn{9}{|l|}{ Any MHS outpatient visits (\%) } \\
\hline 6-Month follow-up & $50.3(6.7)$ & $51.0(5.4)$ & $1.0(0.5-2.0)$ & 0.01 & $55.4(3.4)$ & $54.4(3.6)$ & $0.9(0.6-1.6)$ & 0.02 \\
\hline 12-Month follow-up & $44.4(6.1)$ & $40.3(6.0)$ & $0.8(0.3-2.1)$ & 0.08 & $44.5(3.8)$ & $43.4(3.8)$ & $0.9(0.6-1.5)$ & 0.02 \\
\hline MHS outpatient visits (mean) & & & IRR & & & & IRR & \\
\hline 6-Month follow-up & $7.5(2.6)$ & $8.0(1.7)$ & $1.1(0.5-2.5)$ & 0.03 & $11.7(2.4)$ & $8.0(1.3)$ & $0.7(0.4-1.3)$ & 0.15 \\
\hline 12-Month follow-up & $5.5(1.9)$ & $4.7(1.2)$ & $0.9(0.4-1.9)$ & 0.06 & $6.0(1.0)$ & $4.8(0.5)$ & $0.8(0.5-1.2)$ & 0.09 \\
\hline \multicolumn{9}{|l|}{$\begin{array}{l}\text { MHS outpatient visits in which } \\
\text { advice for medication was } \\
\text { received (mean) }\end{array}$} \\
\hline 6-Month follow-up & $7.0(3.3)$ & $5.3(0.8)$ & $0.8(0.3-2.2)$ & 0.11 & $12.2(2.8)$ & $5.2(0.5)$ & $0.4(0.2-0.7)^{*}$ & 0.30 \\
\hline 12-Month follow-up & $6.4(2.5)$ & $8.2(2.0)$ & $1.3(0.5-3.4)$ & 0.12 & $6.0(1.0)$ & $6.1(0.8)$ & $1.0(0.6-1.6)$ & 0.01 \\
\hline \multicolumn{9}{|l|}{$\begin{array}{l}\text { MHS outpatient visits during } \\
\text { which counseling was received } \\
\text { (mean) }\end{array}$} \\
\hline 6-Month follow-up & $10.5(3.6)$ & $10.7(1.9)$ & $1.0(0.5-2.3)$ & 0.01 & $17.3(3.3)$ & $10.7(1.4)$ & $0.6(0.3-1.2)$ & 0.24 \\
\hline 12-Month follow-up & $9.3(2.6)$ & $10.3(2.4)$ & $1.1(0.5-2.3)$ & 0.06 & $8.9(1.3)$ & $7.7(0.8)$ & $0.9(0.6-1.3)$ & 0.10 \\
\hline $\begin{array}{l}\text { Any outpatient substance abuse } \\
\text { service or self-help group (\%) }\end{array}$ & & & OR & & & & OR & \\
\hline 6-Month follow-up & $22.3(3.9)$ & $28.3(5.5)$ & $1.5(0.6-3.6)$ & 0.14 & $28.0(4.3)$ & $30.6(3.7)$ & $1.2(0.7-2.1)$ & 0.06 \\
\hline 12-Month follow-up & $13.7(3.2)$ & $18.4(3.6)$ & $1.5(0.7-3.3)$ & 0.13 & $18.6(3.0)$ & $20.5(3.3)$ & $1.1(0.6-2.3)$ & 0.05 \\
\hline \multicolumn{9}{|l|}{$\begin{array}{l}\text { Stayed in residential treatment for } \\
\text { substance abuse problem (\%) }\end{array}$} \\
\hline 6-Month follow-up & $12.8(4.1)$ & $12.4(4.1)$ & $1.0(0.4-2.6)$ & 0.01 & $12.8(3.5)$ & $15.1(3.7)$ & $1.3(0.6-2.6)$ & 0.07 \\
\hline 12-Month follow-up & $5.2(2.4)$ & $3.8(2.8)$ & $0.6(0.0-11.6)$ & 0.07 & $7.4(1.9)$ & $5.9(2.0)$ & $0.8(0.3-1.9)$ & 0.06 \\
\hline \multicolumn{9}{|l|}{ Visited primary care (\%) } \\
\hline 6-Month follow-up & $73.0(3.9)$ & $67.5(5.6)$ & $0.8(0.4-1.5)$ & 0.12 & $66.7(3.5)$ & $67.8(3.6)$ & $1.1(0.7-1.6)$ & 0.02 \\
\hline 12-Month follow-up & $71.1(4.9)$ & $68.6(4.7)$ & $0.9(0.4-1.8)$ & 0.05 & $61.1(2.7)$ & $71.7(2.7)$ & $1.7(1.2-2.4)^{*}$ & 0.23 \\
\hline \multicolumn{9}{|l|}{$\begin{array}{l}\text { Visits in community (informal) } \\
\text { sector for depression (mean) }\end{array}$} \\
\hline 6-Month follow-up & $3.7(1.7)$ & $3.0(1.5)$ & $0.8(0.2-3.0)$ & 0.04 & $2.2(0.5)$ & $4.4(1.0)$ & $2.0(1.1-3.9)^{\dagger}$ & 0.15 \\
\hline 12-Month follow-up & $2.5(1.0)$ & $2.5(1.5)$ & $0.9(0.3-3.6)$ & 0.00 & $1.7(0.4)$ & $3.9(1.2)$ & $2.3(1.1-5.1)^{\dagger}$ & 0.14 \\
\hline \multicolumn{9}{|l|}{$\begin{array}{l}\text { Outpatient contacts for depression } \\
\text { all sectors (mean) }\end{array}$} \\
\hline 6-Month follow-up & $16.4(3.8)$ & $19.8(4.8)$ & $1.2(0.6-2.3)$ & 0.09 & $25.0(4.8)$ & $22.6(3.1)$ & $0.9(0.5-1.6)$ & 0.05 \\
\hline 12-Month follow-up & $14.7(4.9)$ & $14.6(3.9)$ & $1.0(0.4-2.2)$ & 0.00 & $19.8(2.8)$ & $18.0(2.6)$ & $0.9(0.6-1.3)$ & 0.04 \\
\hline
\end{tabular}

Data are estimate (standard error) unless otherwise indicated.

Intervention-by-poverty status interaction models used multiple imputed data weighted for the sample eligible for enrollment and accounted for the design effect of the cluster randomization. A logistic regression model was used for a binary variable (presented as odds ratio [OR]) or a Poisson regression model for a count variables (presented as incidence rate ratios [IRR]); adjusted for the baseline status of the dependent variable, age, education, race/ethnicity, 12-month depressive disorder, and community; and accounted for the design effect of the cluster randomization. No significant interactions of intervention by poverty status were found for any outcome variables.

${ }^{*} P<.01$.

${ }^{+} P<.05$.

CEP, Community Engagement and Planning; CI, confidence interval; ES, standardized effect size; MHS, mental health service; RS, Resources for Services. 


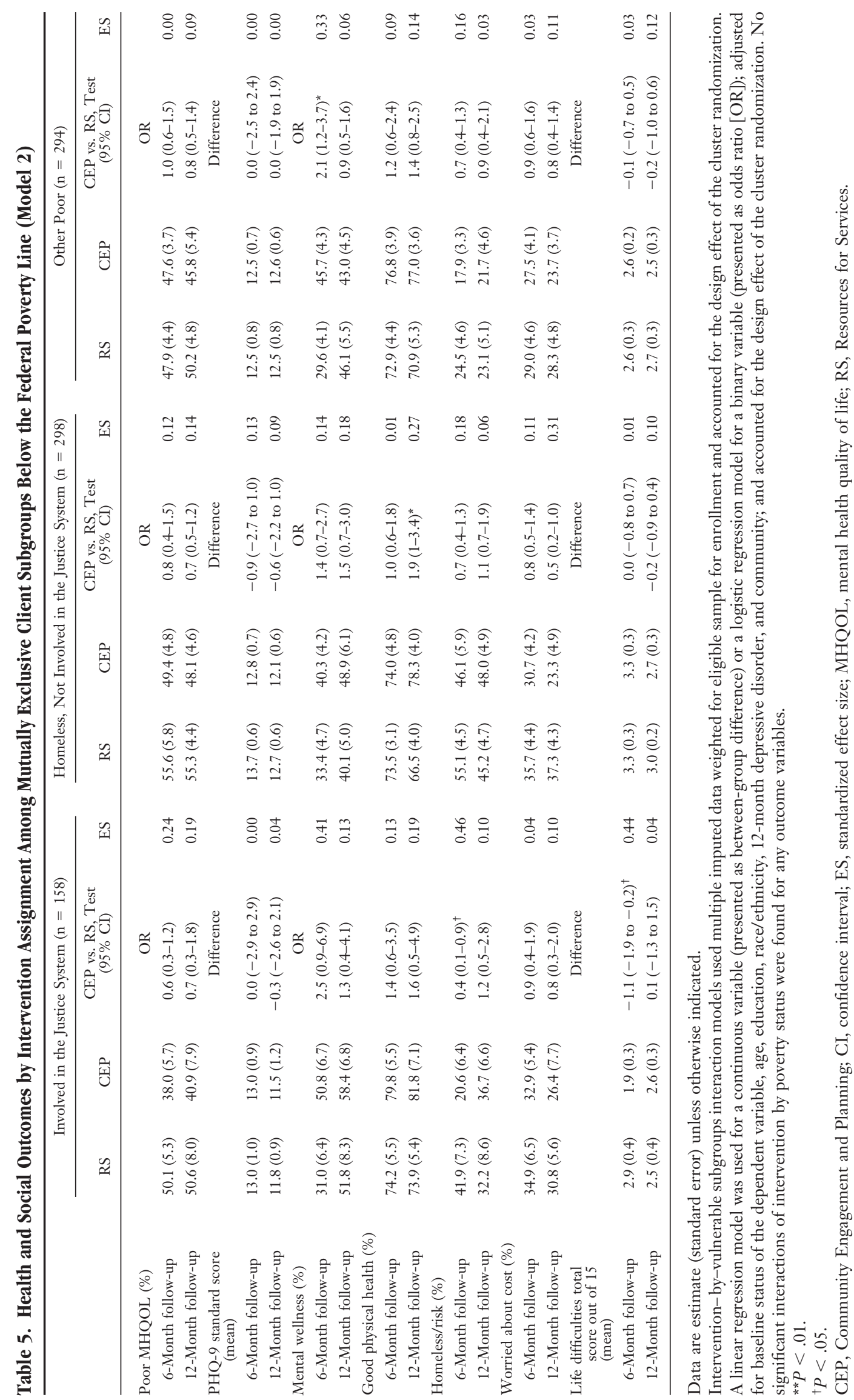


the last 6 months, there was a substantial difference from an average of 35 of 88 clients in the RS group (95\% CI, 20.1-49.1) to 19 of 69 clients in the CEP group (95\% CI, 8.7-28.9). There were no significant findings for social outcomes among the homeless but not justice-involved or other poor subgroups. Regarding utilization outcomes, the percentages of behavioral health hospitalizations, any mental health outpatient visits, and any outpatient or inpatient substance abuse services did not differ significantly by intervention status for subgroups (Table 6). For the justice-involved group, CEP showed suggestive evidence of reducing the number of both MHS medication visits $(P=.038$; $\left.P_{\mathrm{FDR}}=.192 ; \mathrm{ES}=0.31\right)$ and mental health counseling visits $\left(P=.007 ; P_{\mathrm{FDR}}=.066 ; \mathrm{ES}=0.48\right)$ at 6 months. There are no significant utilization outcomes for the homeless who are not justice-involved. Finally, for the other poor subgroup, CEP showed suggestive evidence of shifts in utilization toward community services, such as an increased number of visits in informal sectors in which the client received help for depression or emotional problems at 12 months $\left(P=.050 ; P_{\mathrm{FDR}}=0.281\right.$; $\mathrm{ES}=0.21)$ (Table 6). Detailed results for Model 1 and Model 2 with $P$ values adjusted for false discovery rates for all outcomes are reported in the Online Appendix.

\section{Discussion}

This article examines whether CPIC findings regarding the effects of community engagement and planning, over and above resources for services for the whole sample, also apply among impoverished clients of interest in under-resourced communities, with the nonpoor as a reference group. It also explores effects for low-income subgroups to inform future research. Overall, the pattern of findings suggesting some improved health under CEP compared with RS apply to the poor in terms of mental wellness but not for the primary outcomes of MHQOL and PHQ-9 score; comparable patterns of mental wellness for the nonpoor were not significant given the modest sample size. This is similar to the earlier findings of the Health Insurance Experiment, where variation in the amount of insurance coverage among low-income groups with poor mental health affected psychological well-being rather than distress. ${ }^{46}$ Low-income groups may be more comfortable reporting wellness than dis- tress; or the network-based CEP may have specifically enhanced resiliency over the technical assistance-based RS. Evidence suggesting increased physical activity among the poor under CEP compared with RS was also consistent with overall findings within the sample. In addition, as a new suggestive secondary finding, CEP reduced worry about costs of mental health services, perhaps because of more depression training for cheaper, nonlicensed providers in CEP compared with RS. ${ }^{25}$

In exploring intervention effects for specific poor subgroups (eg, justice-involved, homeless but not justice-involved, other poor), we found no significant effects on preplanned primary outcomes, but we did observe suggestive evidence of $\geq 1$ improved secondary outcome under CEP over RS for each subgroup: reduced homelessness risk factors and life difficulties for the justice-involved, improved physical health for the homeless but not justice-involved, and greater mental wellness for the other poor. Of note, under the community engagement arm relative to RS, fewer justice-involved clients reported having no place to stay, arrests, or being on probation. For the justiceinvolved, many of the intervention effect sizes were large even when not statistically significant (eg, $\mathrm{ES}=0.41$ for mental wellness compared with $\mathrm{ES}=0.33$ among the other poor and $\mathrm{ES}=0.14$ among the homeless but not justice-involved). We also found evidence suggesting fewer MHS visits for medication and counseling in the justice-involved group and of increased use of communitybased depression services among the other poor, both of which are similar to the overall sample. These exploratory findings suggest that it may be important to examine the effects of CEP compared with RS to improve outcomes for depressed clients in larger samples of poor subgroups, especially those who are justice-involved, who tend to have many social and health risks: they are more likely to be homeless ${ }^{47}$; to die of a drug overdose; to commit homicide or suicide or be in an accident after release ${ }^{48,49}$; and to have high levels of chronic medical, mental health, and substance use problems while in prison. ${ }^{35}$ In our sample $>65 \%$ of the justice-involved group are either currently homeless or had multiple risk factors for homelessness at baseline. Since engaging homeless and justice-involved populations was important for CPIC community and policy partners, several enrolled programs provided homeless and/or prisoner reentry 


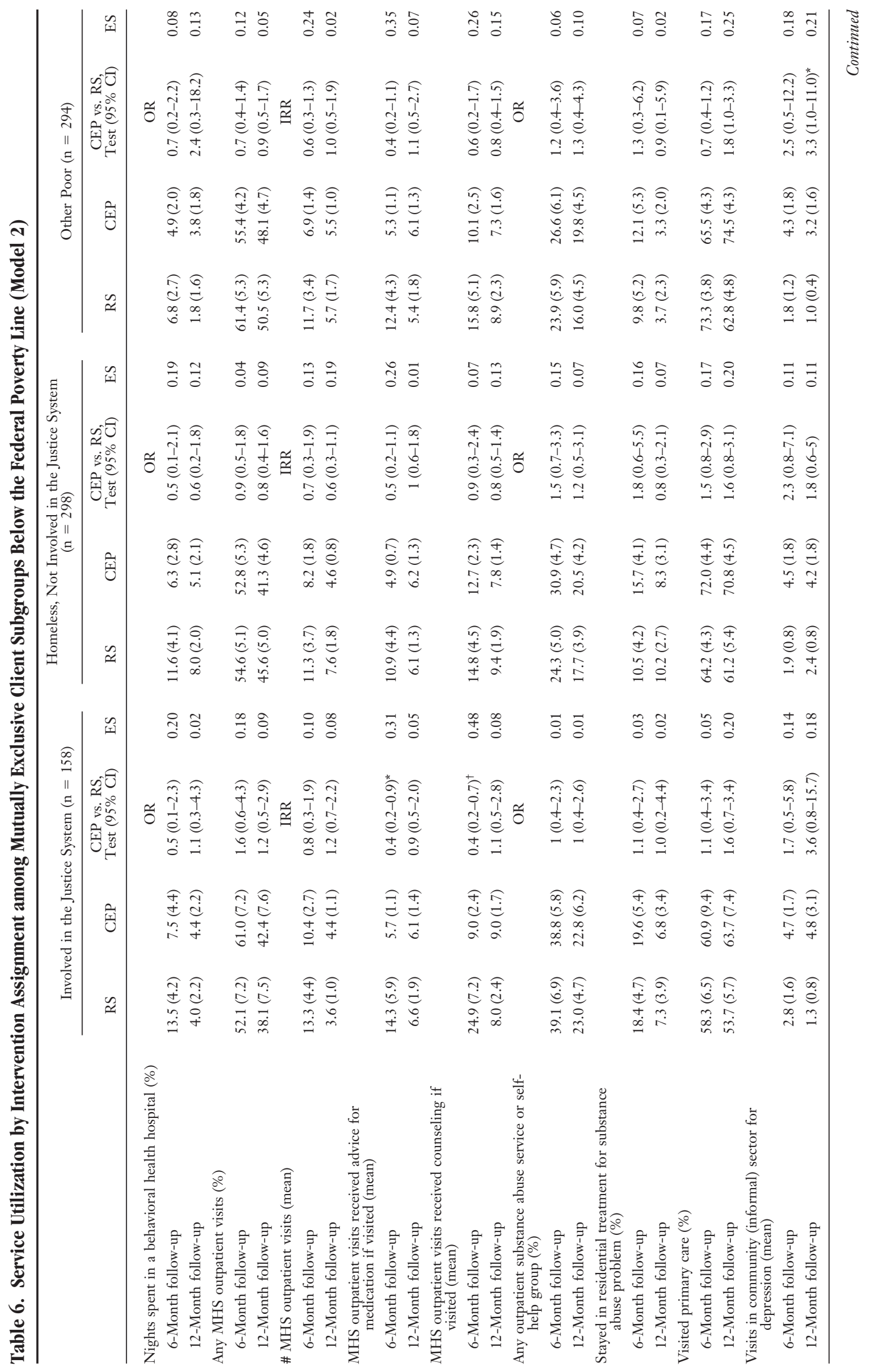


services. The development of a community coalition across health care and community-based service programs-coupled with training in approaches to screen, refer, support coping, and deliver services to depressed clients-may have helped program staff alleviate stressors (eg, lack of food, shelter, clothing) or avoid arrest for those in a (depressed) population that is often difficult to engage in services. This potential to redirect therapeutic skills to enhance social services provision was mentioned by homeless agency staff during training and noted by community leaders while reviewing study findings. Such "task enhancement" may be an important area for future research on low-income populations.

Our findings have limitations. Only 2 communities in 1 large urban area are included and may not generalize to other regions. Interventions were randomized at the program level within the same communities, with potential for contamination (clients receiving services from both CEP and RS agencies). This would reflect a conservative bias (underestimate intervention effects). We are limited by sample size, especially for subgroups. We had multiple secondary outcomes but attempted to mitigate this challenge by reporting ESs and $P_{\mathrm{FDR}}$ along with traditional statistical significance (ie, unadjusted $P$ values). The strongest finding yielded a $P_{\mathrm{FDR}}$ of .027 for mental wellness in subjects living below the FPL; many findings considered as suggestive evidence depended on relaxing the $P_{\mathrm{FDR}}$ threshold to .10 to .20 . We did not have data on important factors such as the chronicity of homelessness, the type of criminal offenses, enrollment in a medical home, and the severity of medical illnesses. Data are based on self-report. Future research is needed using larger sample sizes, more diverse geographic populations, the randomization of whole communities to minimize contamination, and the context of long-term outcomes for systems and clients. The results concern the added value of a community-engaged approach over technical assistance to support agencies in depression QI, not the value of treatment or services delivery per se. In this context one may expect a small ES, and it may be surprising that we observed some sizeable differences.

\section{Conclusion}

The increase in insurance coverage for lower-income populations through the Affordable Care Act 
provides an opportunity to incentivize community health homes, such as integrating primary care in behavioral health settings, ${ }^{50}$ with the potential to reduce disparities in access to and quality of care. Our findings suggest potential areas for future research on coalition approaches to improve outcomes for low-income clients with depression, particularly those who are also justice-involved. The burden of depression in impoverished and vulnerable persons and its collateral effects on communities underscore the need to understand how best to mobilize limited public health and social resources. Compared with more standard technical assistance, CEP offers an approach to better implement depression QI while addressing known disparities in care and outcomes for low-income, depressed clients through health care-community partnerships. The approach and findings of the study presented here recently helped provide an evidence-based foundation for a services model in LA County's Health Neighborhood initiative, which promotes services coordination, quality, and early intervention in mental health. ${ }^{51}$ Given the multiple health and social needs of vulnerable, low-income clients in under-resourced communities, even modest gains across health and/or social indicators can signal important improvements from coalition efforts.

The authors thank Dr. Mitchell H. Katz, Dr. David A. Ganz, and Susan Hirsch for their careful reading of and editorial comments about this manuscript.

\section{References}

1. Insel TR, Charney DS. Research on major depression: strategies and priorities. JAMA 2003;289: 3167-8.

2. Kessler RC, Chiu WT, Demler O, Walters E. Prevalence, severity, and comorbidity of 12-month DSM-IV disorders in the National Comorbidity Survey Replication. Arch Gen Psych 2005;62:61727.

3. Williams DR, Gonzalez HM, Neighbors H, et al. Prevalence and distribution of major depressive disorder in African Americans, Caribbean blacks, and non-Hispanic whites: results from the National Survey of American Life. Arch Gen Psych 2007;64:30515.

4. Jackson-Triche M, Wells KB, Minnium K. Beating depression: the journey to hope. New York: McGraw-Hill; 2002.

5. Alegria M, Chatterji P, Wells KB, et al. Disparity in depression treatment among racial and ethnic mi- nority populations in the United States. Psychiatr Serv 2008;59:1264-72.

6. Katon WJ, Von Korff M, Lin EHB, et al. The Pathways Study: a randomized trial of collaborative care in patients with diabetes and depression. Arch Gen Psych 61:1042, 2004.

7. Asarnow J, Jaycox L, Duan N, et al. Effectiveness of a quality improvement intervention for adolescent depression in primary care clinics. JAMA 2005;293: 311-9.

8. Gilbody S, Bower P, Fletcher J, Richards D, Sutton A. Collaborative care for depression: a cumulative meta-analysis and review of longer-term outcomes. Arch Intern Med 2006;166:2314-21.

9. Gilbody S, Whitty P, Grimshaw J, Thomas R. Educational and organizational interventions to improve the management of depression in primary care. JAMA 2003;289:3145-51.

10. Katon WJ, Lin EHB, Von Korff M, et al. Collaborative care for patients with depression and chronic illnesses. N Engl J Med 2010;363:2611-20.

11. Unützer J, Katon W, Callahan C, et al. Collaborative care management of late-life depression in the primary care setting. JAMA 2002;288:2836-45.

12. Wells KB, Tang L, Miranda J, Benjamin B, Duan N, Sherbourne CD. The effects of quality improvement for depression in primary care at nine years: results from a randomized, controlled group-level trial. Health Serv Res 2008;43:1952-74.

13. Wells KB, Sherbourne C, Schoenbaum M, et al. Impact of disseminating quality improvement programs for depression in managed primary care: a randomized controlled trial. JAMA 2000;283:21220.

14. Wells KB, Jones L, Chung B, et al. Communitypartnered cluster-randomized comparative effectiveness trial of community engagement and planning or resources for services to address depression disparities J Gen Intern Med 2013;28:1268-78.

15. Miranda J, Chung JY, Green BL, et al. Treating depression in predominantly low-income young minority women. JAMA 2003;290:57-65.

16. Wells K, Sherbourne C, Schoenbaum M, et al. Fiveyear impact of quality improvement for depression: results of a group-level randomized controlled trial. Arch Gen Psych 2004;61:378-86.

17. Miranda J, Green BL, Krupnick JI, et al. One-year outcomes of a randomized clinical trial treating depression in low-income minority women. J Consult Clin Psychol 2006;74:99.

18. Miranda J, Duan N, Sherbourne C, et al. Improving care for minorities: can quality improvement interventions improve care and outcomes for depressed minorities? Results of a controlled randomized trial. Health Serv Res 2003;38:613-30.

19. New Freedom Commission on Mental Health. Achieving the promise: transforming mental health 
in America. Rockville, MD: US Department of Health and Human Services; 2003.

20. Miranda J, McGuire T, Williams D, Wang P. Mental health in the context of health disparities. Am J Psychiatry 2008;165:1102-8.

21. World Health Organization. Mental health action plan 2013-2020. Geneva: WHO Press; 2013.

22. Institute of Medicine. Promoting health: intervention strategies from social and behavioral research. Washington, DC: National Academies Press; 2000.

23. Chung B, Ong M, Ettner S, et al. 12-Month outcomes of community engagement versus technical assistance to implement depression collaborative care: a partnered, cluster, randomized, comparative effectiveness trial. Ann Intern Med 2014;161:S23-34.

24. Chung B, Jones L, Dixon E, Miranda J, Wells K. Using a community partnered participatory research approach to implement a randomized controlled trial: Planning Community Partners in Care. J Health Care Poor Underserved 2010;21:780-95.

25. Chung B, Ngo V, Ong M, et al. Participation in training for depression care quality improvement: a randomized trial of community engagement or technical support. Psychiatr Serv 2015;66:831-9.

26. Anderson L, Adeney K, Shinn C, Safranek S, Buckner-Brown J, Krause LK. Community coalitiondriven interventions to reduce health disparities among racial and ethnic minority populations. Cochrane Database Syst Rev 2015;6:CD009905.

27. Sherbourne C, Edelen M, Zhou A, Bird C, Duan N, Wells K. How quality improvement interventions for depression affect life events and psychological well-being over time: a nine-year longitudinal analysis. Med Care 2008;46:78-84.

28. Jones L, Wells K. Strategies for academic and clinician engagement in community-participatory partnered research. JAMA 2007;297:407-10.

29. Miranda J, Ong MK, Jones L, et al. Communitypartnered evaluation of depression services for clients of community-based agencies in under-resourced communities in Los Angeles. J Gen Intern Med 2013;28:1279-87.

30. Kroenke K, Strine T, Spitzer R, Williams J, Berry J, Mokdad A. The PHQ-8 as a measure of current depression in the general population. J Affect Disord 2009; 114:163-73.

31. Sheehan D, Lecrubier Y, Sheehan K, et al. The Mini-International Neuropsychiatric Interview (MINI): the development and validation of a structured diagnostic psychiatric interview for DSM-IV and ICD-10. J Clin Psychiatry 1998;59:22-33.

32. Bush K, Kivlahan D, McDonell M, Fihn S, Bradley K. The AUDIT Alcohol Consumption Questions (AUDIT-C): an effective brief screening test for problem drinking. Arch Intern Med 1998;158:1789-95.

33. Skinner H. The Drug Abuse Screening Test. Addict Behav 1982;7:363-71.

34. Ware J, Kosinski W, Keller S. SF-12: how to score the SF-12 physical and mental health summary scores. Lincoln, RI: Quality-Metric Inc.; 1998.

35. Kroenke K, Spitzer R. The PHQ-9: a new depression diagnostic and severity measure. Psychiatr Ann 2002;32:1-7.

36. Binder D. On the variances of asymptotically normal estimators from complex surveys. Int Stat Rev 1983; 51:279-92.

37. Lavori P, Dawson R, Shera D. A multiple imputation strategy for clinical trials with truncation of patient data. Stat Med 1995;14:1913-25.

38. Benjamini Y, Yekutieli D. The control of the false discovery rate in multiple testing under dependency. Ann Stat 2001;29:1165-88.

39. Benjamini Y, Hochberg Y. Controlling the false discovery rate: a practical and powerful approach to multiple testing. J R Stat Soc Series B Stat Methodol 1995;57:289-300.

40. Yekutieli D, Benjamini Y. A resampling based false discovery rate controlling multiple test procedures for correlated test statistics. J Stat Plan Inference 1999;82:171-96.

41. Miller RG Jr. Beyond ANOVA: basics of applied statistics. New York: John Wiley \& Sons; 1986.

42. Sullivan G, Feinn R. Using effect size-or why the $P$ value is not enough. J Grad Med Educ 2012;4:27982.

43. Cohen J. Statistical power analysis for the behavioral sciences. New York: Academic Press; 1977.

44. Graubard B, Korn E. Predictive margins with survey data. Biometrics 1999;55:652-9.

45. Hedges L. Effect sizes in cluster-randomized designs. J Educ Behav Stat 2007;32:341-70.

46. Wells KB, Manning W, Valdez B. The effects of insurance generosity on the psychological distress and psychological well-being of a general population. Arch Gen Psychiatry 1989;46:315-20.

47. Kushel M, Hahn J, Evans J, Bangsberg D, Moss A. Revolving doors: imprisonment among the homeless and marginally housed population. Am J Public Health 2005;95:1747-52.

48. Binswanger I, Stern M, Deyo R, et al. Release from prison-a high risk of death for former inmates. N Engl J Med 2007;356:157-65.

49. Rosen D, Schoenbach V, Wohl D. All-cause and cause-specific mortality among men released from state prison, 1980-2005. Am J Public Health 2008; 98:2278-84.

50. Barnert E, Perry R, Wells KB. Reforming healthcare for former prisoners. J Gen Intern Med 2014;29: 1093-5.

51. LACDMH encourages care for depression in underserved communities. Los Angeles County Department of Mental Health press release, January 27, 2015. Available from: http://file.lacounty.gov/ dmh/cms1_223766.pdf. Accessed August 30, 2015 . 


\section{Appendix 1. Detailed Results for Model 1 and Model 2 with $P$ Values Adjusted for False Discovery Rates for All Outcomes}

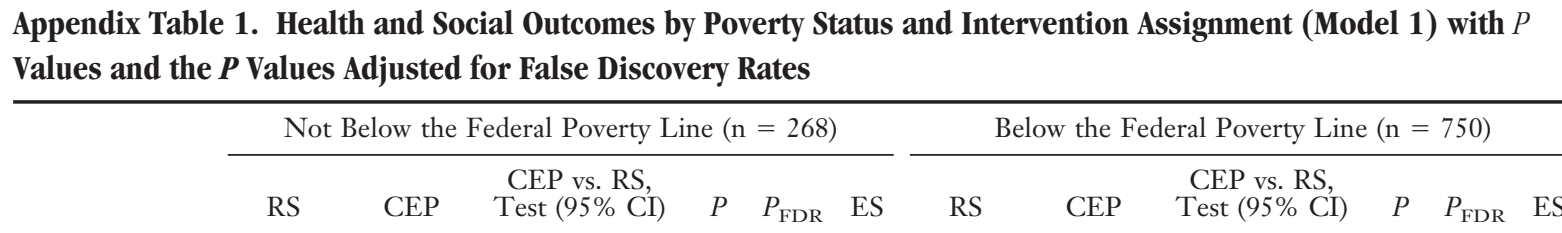

\begin{tabular}{|c|c|c|c|c|c|c|c|c|c|c|c|c|}
\hline $\begin{array}{c}\text { Poor MHQOL } \\
(\%)\end{array}$ & & & OR & & & & & & OR & & & \\
\hline $\begin{array}{l}\text { 6-Month } \\
\text { follow-up }\end{array}$ & $51.4(4.4)$ & $37.0(4.7)$ & $0.5(0.3-1.1)$ & .084 & .554 & 0.29 & $51.6(3.0)$ & $46.5(2.5)$ & $0.8(0.6-1.1)$ & .175 & .394 & 0.10 \\
\hline $\begin{array}{l}\text { 12-Month } \\
\text { follow-up }\end{array}$ & $45.3(4.9)$ & $42.4(5.8)$ & $0.9(0.5-1.6)$ & .689 & .969 & 0.06 & $52.2(3.0)$ & $45.7(3.2)$ & $0.8(0.6-1.1)$ & .107 & .250 & 0.13 \\
\hline $\begin{array}{l}\text { PHQ-8 standard } \\
\text { score } \\
\text { (mean) }\end{array}$ & & & Difference & & & & & & Difference & & & \\
\hline $\begin{array}{l}\text { 6-Month } \\
\text { follow-up }\end{array}$ & $12.1(0.8)$ & $11.8(0.7)$ & $-0.2(-2.6,2.2)$ & .840 & .840 & 0.04 & $13.1(0.5)$ & $12.7(0.5)$ & $-0.4(-2.3,1.4)$ & .596 & .596 & 0.06 \\
\hline $\begin{array}{l}\text { 12-Month } \\
\text { follow-up }\end{array}$ & $10.9(0.9)$ & $10.9(0.8)$ & $0.0(-2.2,2.3)$ & .969 & .969 & 0.00 & $12.4(0.4)$ & $12.1(0.4)$ & $-0.3(-1.5,0.9)$ & .605 & .623 & 0.04 \\
\hline $\begin{array}{l}\text { Mental wellness } \\
(\%)\end{array}$ & & & OR & & & & & & OR & & & \\
\hline $\begin{array}{l}\text { 6-Month } \\
\text { follow-up }\end{array}$ & $40.1(4.9)$ & $49.0(6.5)$ & $1.5(0.6-3.4)$ & .328 & .766 & 0.18 & $31.6(3.0)$ & $44.6(2.6)$ & $1.8(1.2-2.7)$ & .004 & .027 & 0.27 \\
\hline $\begin{array}{l}\text { 12-Month } \\
\text { follow-up }\end{array}$ & $54.7(5.7)$ & $51.0(4.3)$ & $0.9(0.5-1.6)$ & .619 & .969 & 0.07 & $44.8(3.6)$ & $48.2(3.4)$ & $1.2(0.7-1.8)$ & .509 & .623 & 0.07 \\
\hline \multicolumn{13}{|l|}{$\begin{array}{l}\text { Good physical } \\
\text { health (\%) }\end{array}$} \\
\hline $\begin{array}{l}\text { 6-Month } \\
\text { follow-up }\end{array}$ & $78.1(4.3)$ & $80.2(3.9)$ & $1.2(0.5-2.5)$ & .712 & .840 & 0.05 & $73.5(2.8)$ & $76.4(2.2)$ & $1.2(0.8-1.7)$ & .360 & .420 & 0.07 \\
\hline $\begin{array}{l}\text { 12-Month } \\
\text { follow-up }\end{array}$ & $78.0(4.2)$ & $77.4(3.8)$ & $1.0(0.5-1.9)$ & .906 & .969 & 0.01 & $69.6(3.5)$ & $78.4(2.8)$ & $1.6(1.1-2.4)$ & .019 & .115 & 0.20 \\
\hline \multicolumn{13}{|l|}{$\begin{array}{l}\text { Homeless/risk } \\
(\%)\end{array}$} \\
\hline $\begin{array}{l}\text { 6-Month } \\
\text { follow-up }\end{array}$ & $38.1(6.6)$ & $27.9(4.8)$ & $0.6(0.3-1.2)$ & .158 & .554 & 0.22 & $40.3(3.4)$ & $30.3(3.1)$ & $0.6(0.4-1.0)$ & .050 & .176 & 0.21 \\
\hline $\begin{array}{l}\text { 12-Month } \\
\text { follow-up }\end{array}$ & $25.7(4.1)$ & $31.0(5.3)$ & $1.3(0.7-2.5)$ & .400 & .969 & 0.12 & $33.8(3.6)$ & $35.7(3.5)$ & $1.1(0.8-1.6)$ & .623 & .623 & 0.04 \\
\hline \multicolumn{13}{|l|}{$\begin{array}{c}\text { Worried about } \\
\text { cost }(\%)\end{array}$} \\
\hline $\begin{array}{l}\text { 6-Month } \\
\text { follow-up }\end{array}$ & $29.5(4.5)$ & $32.2(5.8)$ & $1.1(0.5-2.7)$ & .755 & .840 & 0.06 & $33.0(2.7)$ & $29.6(2.6)$ & $0.9(0.6-1.2)$ & .334 & .420 & 0.07 \\
\hline $\begin{array}{l}\text { 12-Month } \\
\text { follow-up }\end{array}$ & $28.7(4.8)$ & 30.1 (4.6) & $1.1(0.6-2.0)$ & .820 & .969 & 0.03 & $32.6(2.6)$ & $24.0(3.2)$ & $0.6(0.4-1.0)$ & .033 & .115 & 0.19 \\
\hline $\begin{array}{l}\text { Life difficulties } \\
\text { total score } \\
\text { out of } 15 \\
\text { (mean) }\end{array}$ & & & Difference & & & & & & Difference & & & \\
\hline $\begin{array}{l}\text { 6-Month } \\
\text { follow-up }\end{array}$ & $3.0(0.3)$ & $2.7(0.3)$ & $-0.3(-1.0,0.5)$ & .491 & .840 & 0.12 & $3.0(0.2)$ & $2.7(0.1)$ & $-0.3(-0.7,0.2)$ & .225 & .394 & 0.12 \\
\hline $\begin{array}{l}\text { 12-Month } \\
\text { follow-up }\end{array}$ & $2.6(0.2)$ & $2.4(0.2)$ & $-0.2(-0.9,0.4)$ & .499 & .969 & 0.09 & $2.8(0.2)$ & $2.6(0.2)$ & $-0.2(-0.5,0.2)$ & .376 & .623 & 0.09 \\
\hline
\end{tabular}

Data are estimate (standard error) unless otherwise indicated.

Intervention-by-poverty status interaction models were used multiple imputed data, were weighted for eligible sample for enrollment, and accounted for the design effect of the cluster randomization. A linear regression model was used for continuous variables (presented as the between-group difference) and a logistic regression model was used for binary variables (presented as odds ratio $[\mathrm{OR}]$ ), adjusted for baseline status of the dependent variable, age, education, race/ethnicity, 12-month depressive disorder, and community. No significant interactions of intervention and poverty status were found for any outcome variables.

CEP, Community Engagement and Planning; CI, confidence interval; ES, standardized effect size; MHQOL, mental health quality of life; $P_{\mathrm{FDR}}, P$ value adjusted for false discovery rate; PHQ-8, 8-item Patient Health Questionnaire; RS, Resources for Services. 


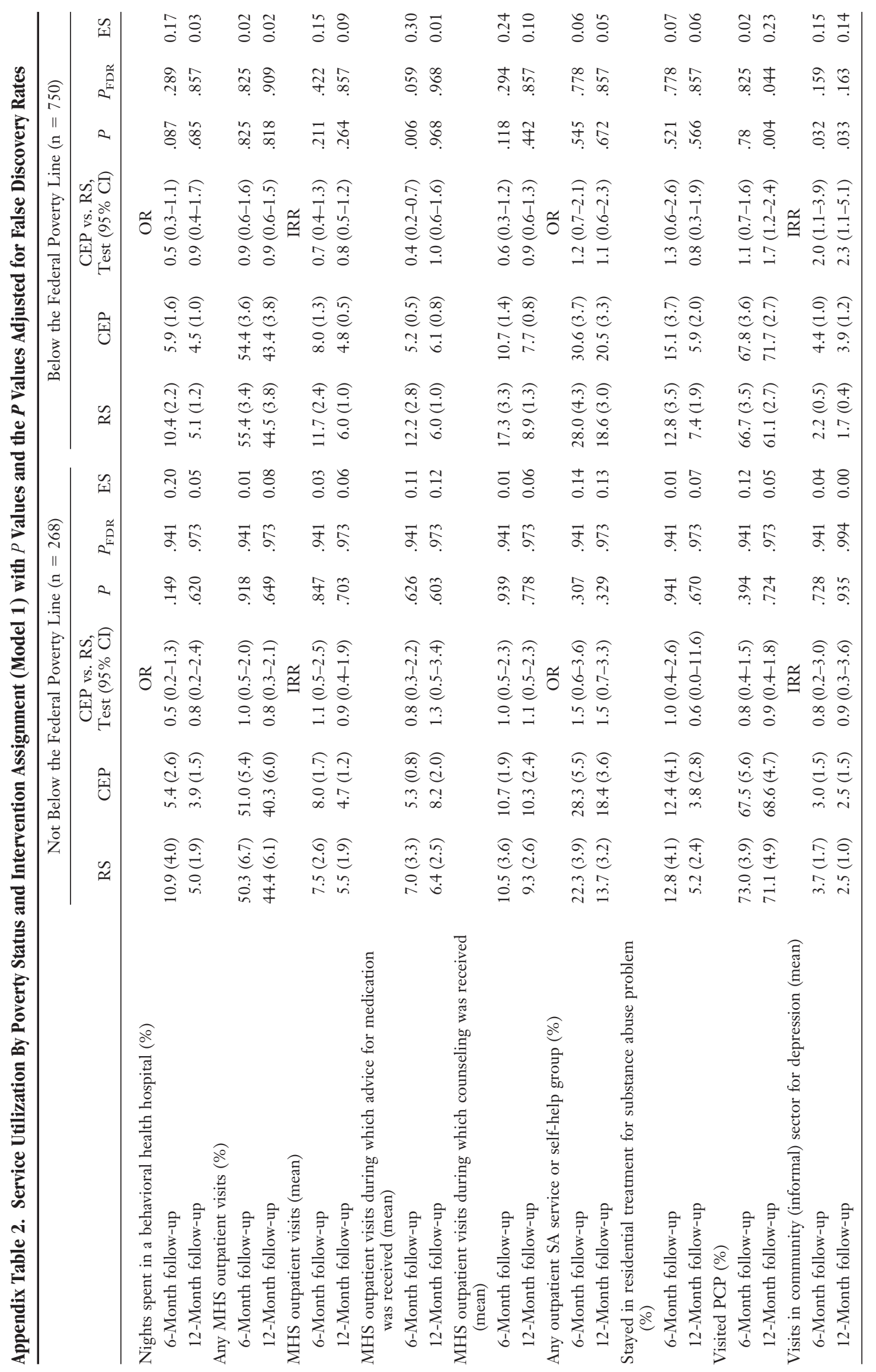




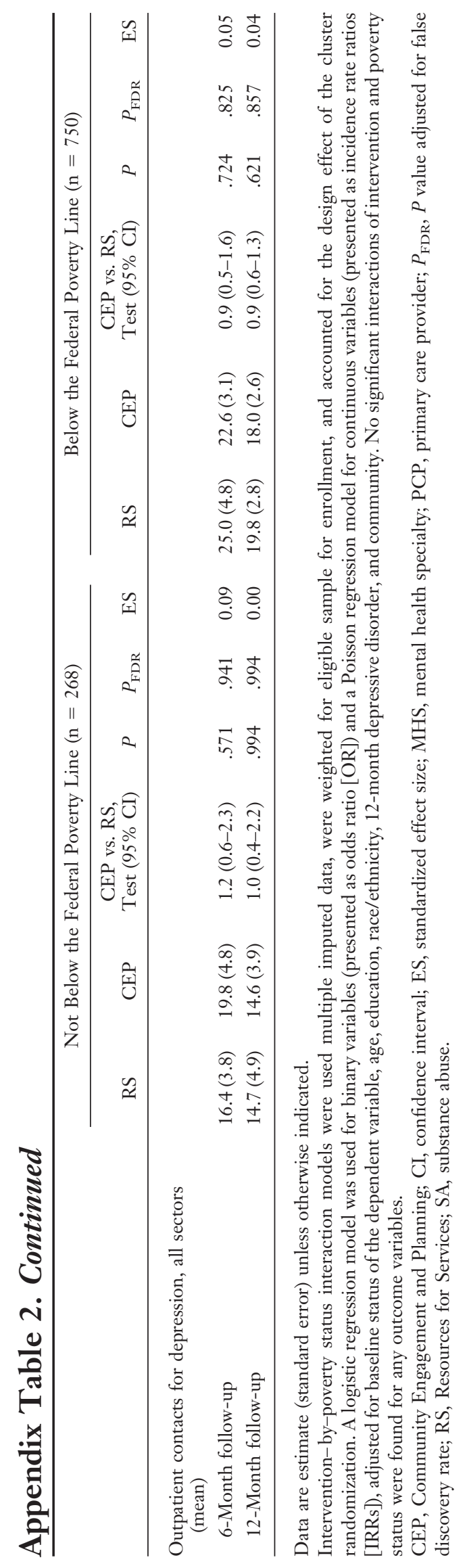




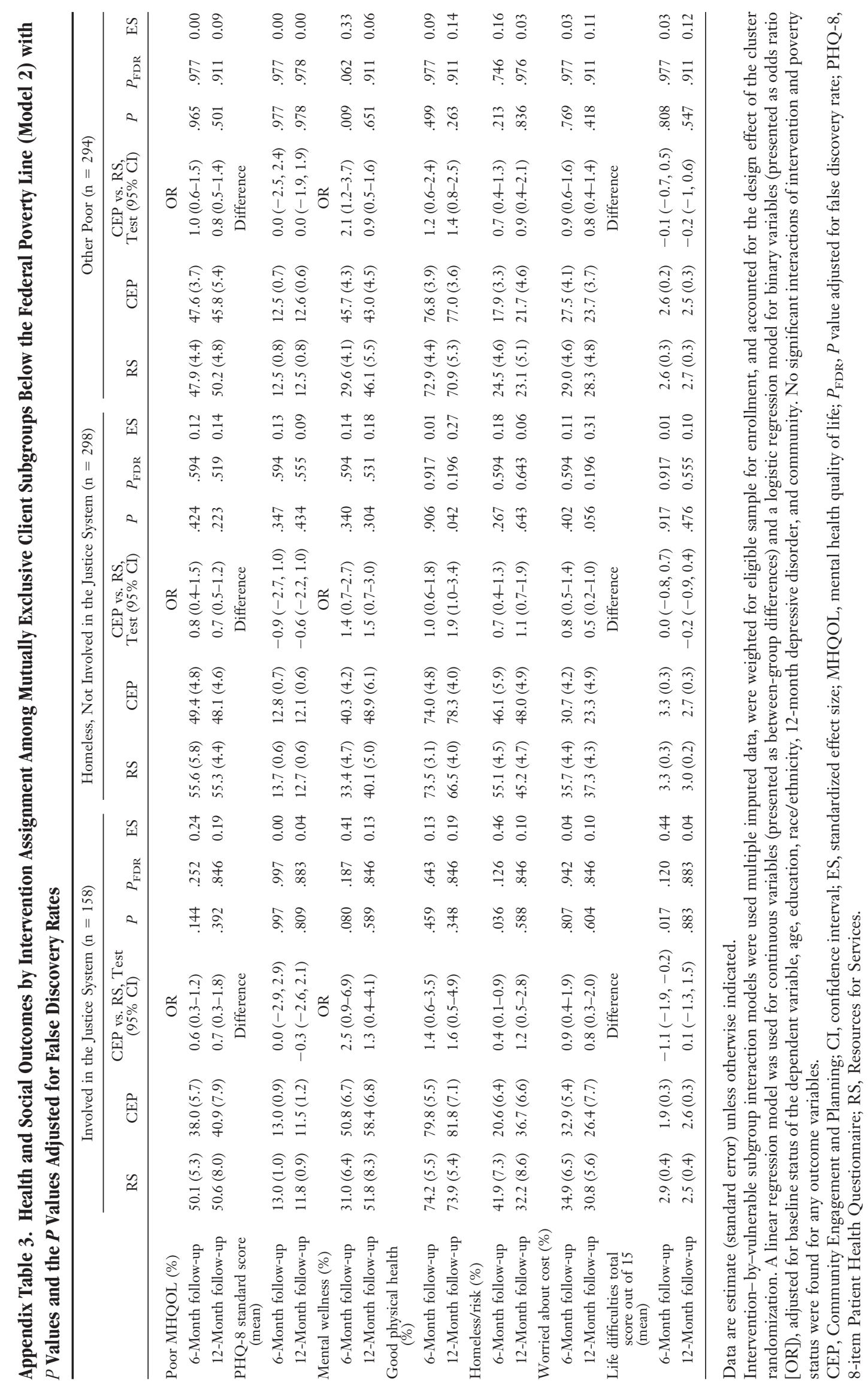




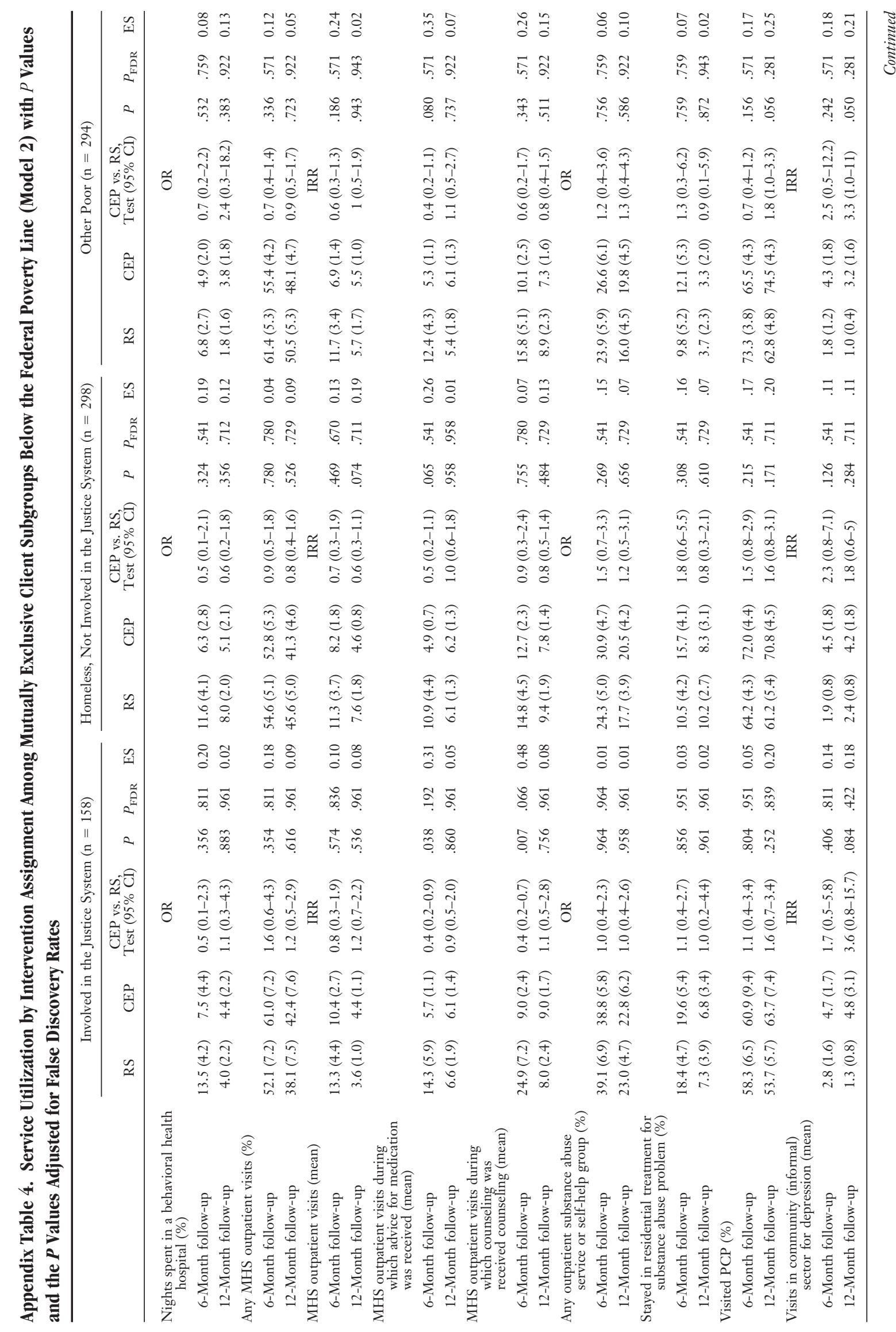




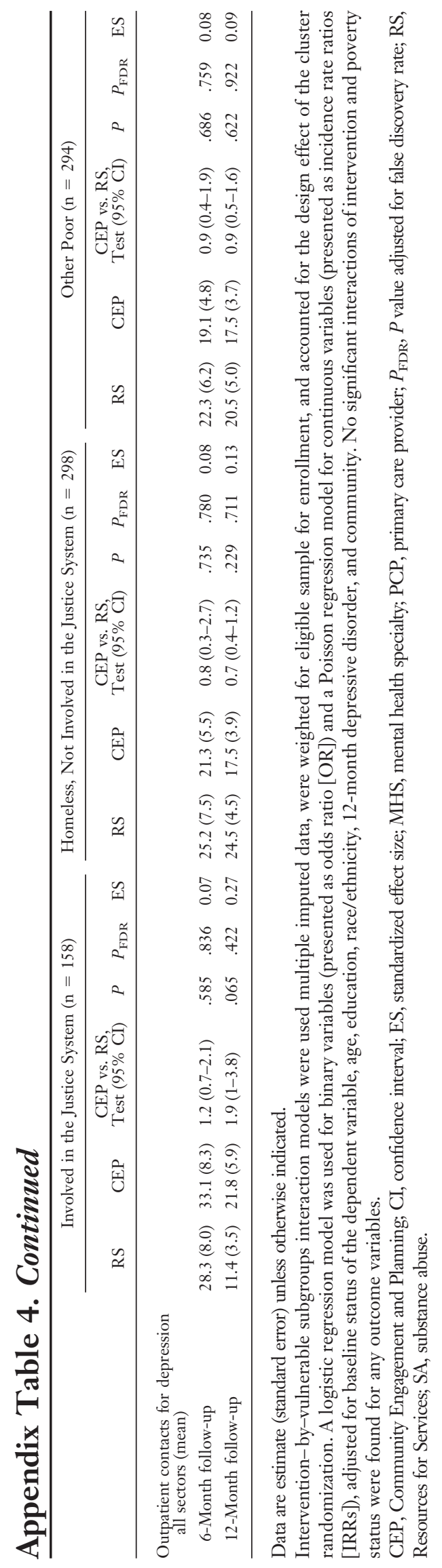

